\title{
Long-term clinical and radiographic outcomes of the Prestige LP artificial cervical disc replacement at 2 levels: results from a prospective randomized controlled clinical trial
}

\author{
Todd H. Lanman, MD, J. Kenneth Burkus, MD, ${ }^{2}$ Randall G. Dryer, MD, ${ }^{3}$ Matthew F. Gornet, MD, ${ }^{4}$ \\ Jeffrey McConnell, MD, ${ }^{5}$ and Scott D. Hodges, DO ${ }^{6}$ \\ ${ }^{1}$ Institute for Spinal Disorders, Cedars-Sinai Medical Center, Los Angeles, California; ${ }^{2}$ Wilderness Spine Services, Columbus, \\ Georgia; ${ }^{3}$ Central Texas Spine Institute, Austin, Texas; ${ }^{4}$ The Orthopedic Center of St. Louis, Missouri; ${ }^{5}$ Orthopedic Specialists, \\ Allentown, Pennsylvania; and ${ }^{6}$ Center for Sports Medicine \& Orthopaedics, Chattanooga, Tennessee
}

OBJECTIVE The aim of this study was to assess long-term clinical safety and effectiveness in patients undergoing anterior cervical surgery using the Prestige LP artificial disc replacement (ADR) prosthesis to treat degenerative cervical spine disease at 2 adjacent levels compared with anterior cervical discectomy and fusion (ACDF).

METHODS A prospective, randomized, controlled, multicenter FDA-approved clinical trial was conducted at 30 US centers, comparing the low-profile titanium ceramic composite-based Prestige LP ADR $(n=209)$ at 2 levels with ACDF $(n=$ 188). Clinical and radiographic evaluations were completed preoperatively, intraoperatively, and at regular postoperative intervals to 84 months. The primary end point was overall success, a composite variable that included key safety and efficacy considerations.

RESULTS At 84 months, the Prestige LP ADR demonstrated statistical superiority over fusion for overall success (observed rate $78.6 \%$ vs $62.7 \%$; posterior probability of superiority [PPS] $=99.8 \%)$, Neck Disability Index success $(87.0 \%$ vs $75.6 \%$; PPS $=99.3 \%$ ), and neurological success (91.6\% vs $82.1 \%$; PPS $=99.0 \%)$. All other study effectiveness measures were at least noninferior for ADR compared with ACDF. There was no statistically significant difference in the overall rate of implant-related or implant/surgical procedure-related adverse events up to 84 months $(26.6 \%$ and $27.7 \%$, respectively). However, the Prestige LP group had fewer serious (Grade 3 or 4) implant- or implant/surgical procedure-related adverse events $(3.2 \%$ vs $7.2 \%$, log hazard ratio [LHR] and $95 \%$ Bayesian credible interval $[95 \% \mathrm{BCl}]-1.19[-2.29$ to $-0.15])$. Patients in the Prestige LP group also underwent statistically significantly fewer second surgical procedures at the index levels (4.2\%) than the fusion group (14.7\%) (LHR -1.29 [95\% BCl -2.12 to -0.46$]$ ). Angular range of motion at superior- and inferior-treated levels on average was maintained in the Prestige LP ADR group to 84 months.

CONCLUSIONS The low-profile artificial cervical disc in this study, Prestige LP, implanted at 2 adjacent levels, maintains improved clinical outcomes and segmental motion 84 months after surgery and is a safe and effective alternative to fusion.

Clinical trial registration no:: NCT00637156 (clinicaltrials.gov)

https://thejns.org/doi/abs/10.3171/2016.11.SPINE16746

KEY WORDS cervical degenerative disc disease; cervical disc arthroplasty; Prestige LP disc replacement; artificial cervical disc; 2-level disc disease

ABBREVIATIONS ACDF = anterior cervical discectomy and fusion; $A D R=$ artificial disc replacement; $A E=$ adverse event; $B C l=$ Bayesian credible interval; $D D D=$ degenerative disc disease; FSU = functional spinal unit; $\mathrm{HO}=$ heterotopic ossification; LHR = log hazard ratio; MCS = Mental Component Summary; NDI = Neck Disability Index; PCS = Physical Component Summary; PPS = posterior probability of superiority; TDR = total disc replacement.

SUBMITTED June 28, 2016. ACCEPTED November 1, 2016.

INCLUDE WHEN CITING Published online April 7, 2017; DOI: 10.3171/2016.11.SPINE16746. 
A NTERIOR cervical discectomy and fusion (ACDF) is a standard surgical procedure for treating cervical degenerative disc disease (DDD) associated with intractable radiculopathy or myelopathy. However, ACDF significantly limits the segmental motion at adjacent vertebrae, altering the biomechanics of the spine and creating abnormal loads, ${ }^{5,22}$ which may place additional stress on the adjacent discs, possibly resulting in accelerated degeneration of those discs. ${ }^{8,17,22} \mathrm{Re}$ cent studies have demonstrated that cervical total disc replacement (TDR) is a safe and effective alternative to ACDF for treatment at a single level of the cervical spine, and that cervical TDR preserves segmental motion and maintains normal intervertebral disc space height at the treated level. ${ }^{2-4,6,11,14,15,18}$

Many patients have multilevel disease, and 2-level ACDF procedures may result in even greater stresses to the adjacent discs, potentially accelerating adjacent-level disc degeneration. ${ }^{12}$ Furthermore, pseudarthrosis in multilevel ACDF is considerably higher than single-level ACDF, as are revisions, complications, and reoperations..$^{19,20}$ For these reasons, TDR may represent an effective alternative to ACDF for treating multilevel degenerative disc disease.

The Prestige LP cervical disc (Medtronic, Inc.), an artificial disc replacement (ADR) device, was approved by the FDA for treating single-level DDD and intractable radiculopathy or myelopathy. ${ }^{9}$ A clinical trial was initiated in 2006 to evaluate the safety and effectiveness of Prestige LP cervical discs at 2 adjacent levels compared with ACDF. The primary outcome measure was overall success at 24 months after surgery. The overall study success rates were $81.4 \%$ and $69.4 \%$ for the Prestige LP ADR and ACDF groups, respectively. ${ }^{10}$ Both noninferiority and superiority in overall success, the primary study end point, were established for ADR compared with ACDF. Overall, the findings indicate that Prestige LP ADR at 2 levels is at least as safe and effective as ACDF, up to 24 months after surgery, and it was granted marketing approval by the FDA for treating 2-level DDD and intractable radiculopathy or myelopathy in 2016.

The present study assessed the long-term effectiveness and safety of the Prestige LP ADR at 2 contiguous levels by comparing outcomes up to 84 months postoperatively with those for the ACDF treatment group.

\section{Methods}

The FDA granted final approval of an IDE application (G050202) for this study in January 2006, and surgeries occurred between June 2006 and November 2007 (clinical trial registration no.: NCT00637156 [clinicaltrials. gov]). The study protocol and informed consent form were reviewed by independent IRBs at each investigational site (30 sites) and received IRB approval before the study began (Appendix). The prospective, randomized, multicenter, controlled study was designed to assess the safety and effectiveness of the investigational treatment (2-level Prestige LP artificial cervical disc replacement) compared with the control treatment (2-level ACDF procedure involving a cortical ring allograft and the Atlantis Cervical Plate System, Medtronic, Inc.) in patients with intractable radiculopathy and/or myelopathy at 2 adjacent levels of the cervical spine. Blinding of patients and surgeon investigators was not feasible or considered appropriate beyond the screening and informed consent process. Informed consent was obtained from all patients. The specific methods and procedures for the clinical trial have been described in detail elsewhere ${ }^{10}$ and are similar to those reported for the single-level study, ${ }^{9}$ but are summarized here.

\section{Patients}

A sample size calculation for the primary study hypothesis of noninferiority in overall success of the Prestige LP ADR compared with ACDF at 24 months-based on assumed success rates of $72 \%$ and $70 \%$ in the investigational and control groups, respectively, a noninferiority margin (delta) of $10 \%$, an alpha level of 0.05 , and power of $80 \%$-yielded a requirement for 177 patients in each group (354 patients). Allowing for a possible 15\% loss to follow-up, the enrollment goal was $420 \pm 10$ patients at a maximum of 30 sites. Inclusion and exclusion criteria are listed in Table 1. Whether patients met the few subjective criteria was left to the judgment of the surgeons based on their clinical expertise. Patients were randomized in a 1:1 ratio to receive either the investigational device (Prestige LP ADR) or fusion control treatment (ACDF). The randomization schedule was centrally generated by the sponsor's statistician.

A total of 456 patients signed the informed consent forms and were randomized into the 2 treatment groups. However, 42 patients assigned to the ACDF group and 17 patients assigned to the Prestige LP group did not complete the study treatment for reasons including deciding not to have surgery or a change in condition, not wanting randomized treatment (9 of the ACDF patients), insurance issues, or other reasons. In total, 397 patients (209 in the ADR group and 188 in the ACDF group) were treated with the assigned treatment. Patient enrollment and follow-up information are provided in the CONSORT flow diagram (Fig. 1). At 60 months postoperatively, 167 patients in the Prestige LP ADR group and 138 in the ACDF group completed all evaluations required to assess overall success; at 84 months, 154 and 126, respectively, did so, yielding follow-up rates of $76.2 \%$ for the ADR group and $74.1 \%$ for the ACDF group after excluding deaths and withdrawals. All but 3 withdrawals were initiated by the patients after surgery, most commonly because they found the study requirements too demanding (e.g., too much time involved, too many visits), they were feeling better and did not feel they needed to see the doctor, or they were moving from the area. Other patients were lost to follow-up over time, most frequently because of lack of contact information after moving out of the area or unwillingness to undergo further evaluations.

The treatment groups were similar demographically (Table 2), with no statistically significant differences ( $\mathrm{p} \leq$ 0.05 ) except preoperative work status, which was not considered to be a clinically important difference. Preoperative medical history was similar in the 2 treatment groups, and the patients did not differ in any relevant preoperative medical conditions or medication usage, including time 
TABLE 1. Inclusion and exclusion criteria

\begin{tabular}{|c|c|}
\hline Inclusion Criteria & Exclusion Criteria \\
\hline $\begin{array}{l}\text { Cervical DDD at } 2 \text { adjacent cervical levels (from } \mathrm{C}-3 \text { to } \\
\text { C-7) requiring surgical treatment \& involving intractable } \\
\text { radiculopathy, myelopathy, or both } \\
\text { Herniated disc \&/or osteophyte formation at each level } \\
\text { to be treated, producing symptomatic nerve root \&/or } \\
\text { spinal cord compression. The condition documented } \\
\text { by patient history (e.g., neck \&/or arm pain, functional } \\
\text { deficit \&/or neurological deficit), \& the requirement for } \\
\text { surgical treatment evidenced by radiographic studies } \\
\text { (e.g., CT, MRI, radiographs) }\end{array}$ & $\begin{array}{l}\text { Cervical spinal condition other than symptomatic cervical DDD requiring surgical treat- } \\
\text { ment at the involved levels } \\
\text { Documented or diagnosed cervical instability relative to adjacent segments at either level, } \\
\text { defined by dynamic (flexion/extension) radiographs showing sagittal plane translation } \\
>3.5 \mathrm{~mm} \text { or sagittal plane angulation }>20^{\circ} \\
>2 \text { cervical levels requiring surgical treatment } \\
\text { A fused level adjacent to the levels to be treated } \\
\text { Severe pathology of the facet joints of the involved VBs } \\
\text { Previous surgical intervention at either } 1 \text { or both of the involved levels or at adjacent } \\
\text { levels }\end{array}$ \\
\hline $\begin{array}{l}\text { Unresponsive to nonoperative treatment for } \geq 6 \text { wks or } \\
\text { presence of progressive symptoms or signs of nerve } \\
\text { root/spinal cord compression in the face of continued } \\
\text { nonoperative management }\end{array}$ & $\begin{array}{l}\text { Previously diagnosed w/ osteopenia or osteomalacia } \\
\text { If risk factor for osteoporosis, a DEXA scan was required to determine eligibility; a T } \\
\text { score of }-3.5 \text { or lower (e.g., }-3.6,-3.7 \text { ) or a T score of }-2.5 \text { or lower (e.g., }-2.6,-2.7 \text { ) } \\
\text { w/ vertebral crush fracture, excluded the patient from the study }\end{array}$ \\
\hline $\begin{array}{l}\text { No previous surgical intervention at the involved levels or } \\
\text { any subsequent planned/staged surgical procedure at } \\
\text { the involved or adjacent level(s) }\end{array}$ & $\begin{array}{l}\text { Presence of spinal metastases } \\
\text { Overt or active bacterial infection, either local or systemic } \\
\text { Insulin-dependent diabetes }\end{array}$ \\
\hline $\begin{array}{l}\geq 18 \text { yrs old \& skeletally mature at the time of surgery } \\
\text { Preop NDI score } \geq 30\end{array}$ & or whe did not aren to cuenend cmoking nrior to au \\
\hline $\begin{array}{l}\text { Preop neck pain score } \geq 8 \text { based on the preop neck } \& \text { arm } \\
\text { pain questionnaire }\end{array}$ & $\begin{array}{l}\text { Documented allergy or intolerance to stainless steel, titanium, or a titanium alloy } \\
\text { Belonged to a vulnerable population (e.g., mentally incompetent, prisoner, pregnant) }\end{array}$ \\
\hline $\begin{array}{l}\text { If a female of childbearing potential, nonpregnant, non- } \\
\text { nursing, and agreed not to become pregnant during the } \\
\text { study period } \\
\text { Willing to comply w/ the study plan \& sign the patient } \\
\text { informed consent form }\end{array}$ & $\begin{array}{l}\text { Alcohol \&/or drug abuser as defined by undergoing treatment for alcohol \&/or drug abuse } \\
\text { Involved w/ current or pending litigation regarding a spinal condition } \\
\text { Received drugs that may interfere w/ bone metabolism w/in } 2 \text { wks prior to the planned } \\
\text { date of spinal surgery (e.g., steroids or methotrexate), excluding routine perioperative } \\
\text { antiinflammatory drugs }\end{array}$ \\
\hline
\end{tabular}

DEXA = dual-energy $\mathrm{x}$-ray absorptiometry; $\mathrm{VB}=$ vertebral body.

from symptom onset to surgery, previous neck surgery, or pain medication usage. Table 3 shows the distribution of presenting complaints for the 2 groups. Finally, there were no significant preoperative differences between groups in any of the clinical measures.

\section{Materials}

\section{Investigational Device}

The Prestige LP Cervical Disc is a dynamic device made of a titanium alloy/titanium carbide composite (also referred to as a titanium ceramic composite) (Fig. 2). The devices are implanted through an anterior approach after a discectomy and are available in various sizes to accommodate the intervertebral disc space and to engage the adjacent vertebral bodies. Device components are placed into the vertebral bodies through impaction at surgery and maintained via bony ingrowth over time.

\section{Outcome Measures}

The primary end point was overall success, a composite of both safety and efficacy end points. A patient was considered to have attained overall success if postoperative improvement in the Neck Disability Index (NDI) ${ }^{21}$ score was at least 15 points, neurological status did not worsen, and no serious implant-associated or implant/surgical procedure-associated adverse event (AE) occurred, including a second surgery at the treatment level classified as a supplemental fixation, revision, or nonelective remov- al. Definitions of success for individual efficacy measures are shown in Table 4.

Other efficacy and safety outcome measures included neck and arm pain rating scales adapted from a previously defined scale, ${ }^{13}$ which produced a total pain score based on both intensity and frequency, the Medical Outcomes Study SF-36 ${ }^{23}$ Physical Component Summary (PCS) and Mental Component Summary (MCS), gait assessment (Nurick's Classification ${ }^{16}$ ), radiographic assessments (disc height measurement, or functional spinal unit [FSU], heterotopic ossification [HO] in the ADR group graded from 0 to IV, implant condition), patient satisfaction (3 questions, 5-point scale ranging from "definitely true" to "definitely false"), patient global perceived effect (7-point scale from "completely recovered" to "vastly worsened"), foraminal compression test, work status including time to return to work after surgery, physician's perception of results ("excellent," "good," "fair," or "poor"), AE including severity (Grades 1-4) and possible association with the implant and/or surgical procedure assessed by an independent Clinical Adjudication Committee, neurological status, and second surgical procedures that were classified as revision, removal, supplemental fixation, reoperation, or other.

\section{Procedures}

Baseline evaluations, including basic demographics; medical history; assessments of pain, disability, and 


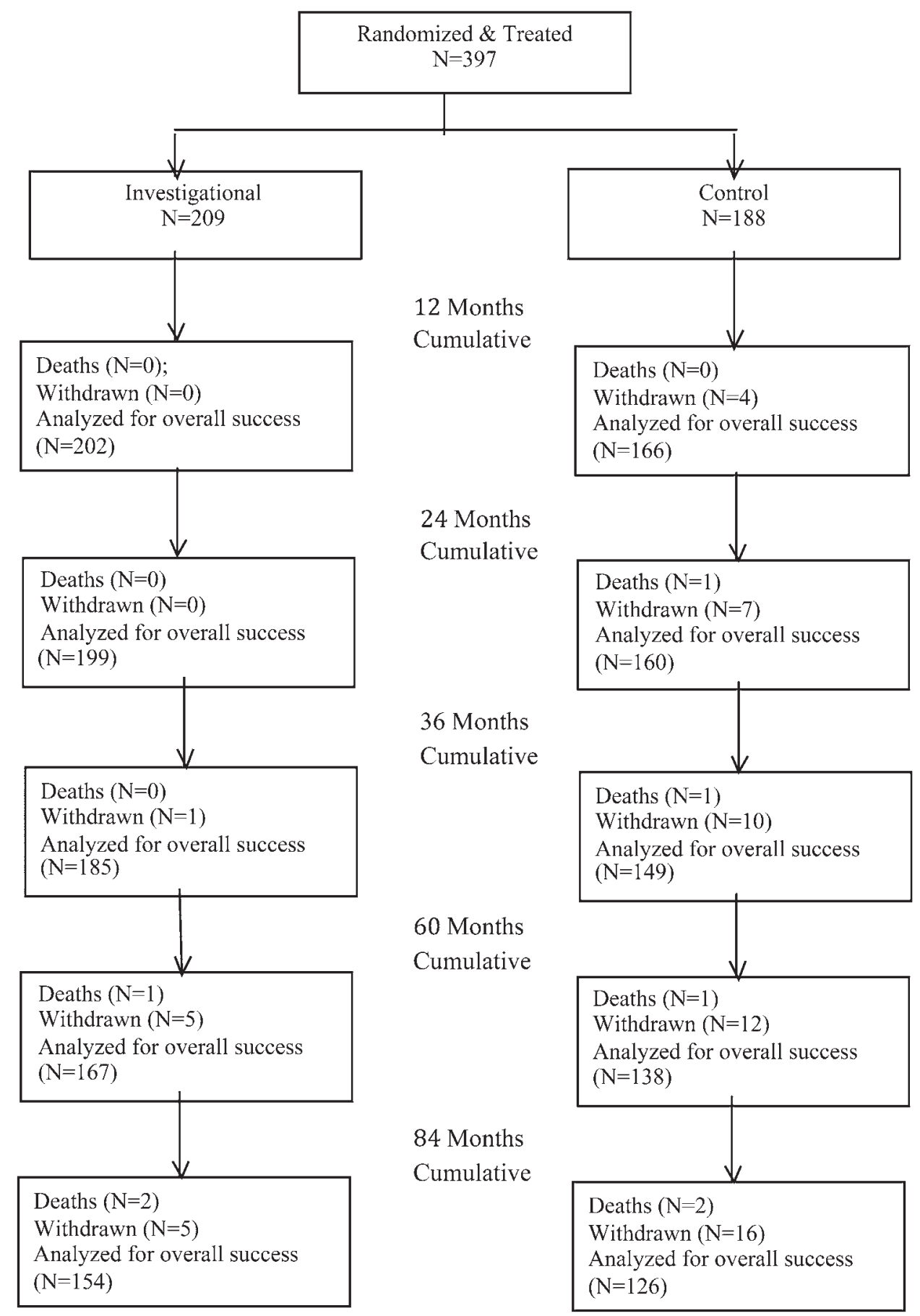

FIG. 1. CONSORT flowchart of participants throughout the 84-month study. Numbers shown in each box are cumulative through the time period.

neurological status; and radiographic evaluation, were conducted before surgery. Additional radiographs of the treated area were obtained before patients left the facility; surgical data were also collected.

Patient evaluations were scheduled to occur preoperatively (within 6 months of surgery), at surgery, and postoperatively at 6 weeks ( \pm 2 weeks), 3 months ( \pm 2 weeks), 6 months ( \pm 1 month), 12 months ( \pm 2 months), 24 months ( \pm 2 months), 36 months ( \pm 2 months), 60 months ( \pm 3 months), 84 months ( \pm 3 months), and 120 months ( \pm 3 months). At this time, follow-ups through 84 months have been completed, and those findings are reported here.

\section{Radiographic Measurements}

Images obtained at study sites were sent to a central core laboratory (Biomedical Systems) for independent review by 2 primary reviewers using a proprietary imaging archival system and software-based measurement tools 
TABLE 2. Demographic characteristics of the Prestige LP ADR and the fusion treatment ACDF groups at baseline

\begin{tabular}{|c|c|c|c|}
\hline Variable & $\begin{array}{c}\text { Prestige LP } \\
\text { ADR }(n=209)\end{array}$ & $\begin{array}{c}\text { ACDF } \\
(n=188)\end{array}$ & $p$ Value \\
\hline Age (yrs) & & & 0.84 (NS) \\
\hline Mean (SD) & $47.1(8.3)$ & $47.3(7.7)$ & \\
\hline Min-max & $22.0-75.0$ & $25.0-69.0$ & \\
\hline Height (inches) & & & 0.28 (NS) \\
\hline Mean (SD) & $67.2(3.9)$ & $67.6(4.0)$ & \\
\hline Min-max & $59.0-77.0$ & $60.0-78.0$ & \\
\hline Weight (lbs) & & & 0.30 (NS) \\
\hline Mean (SD) & $182.1(42.6)$ & $186.3(37.2)$ & \\
\hline Min-max & $105.0-360.0$ & $106.0-300.0$ & \\
\hline Body mass index & & & 0.48 (NS) \\
\hline Mean (SD) & $28.2(5.6)$ & $28.6(4.9)$ & \\
\hline Min-max & $16.4-46.1$ & $18.0-43.4$ & \\
\hline Sex, n (\%) & & & 0.48 (NS) \\
\hline Male & $92(44.0)$ & $90(47.9)$ & \\
\hline Female & $117(56.0)$ & $98(52.1)$ & \\
\hline Race, n (\%) & & & 0.88 (NS) \\
\hline Caucasian & 195 (93.3) & $172(91.5)$ & \\
\hline Black & $8(3.8)$ & $8(4.3)$ & \\
\hline Asian & $1(0.5)$ & $3(1.6)$ & \\
\hline Hispanic & $4(1.9)$ & $4(2.1)$ & \\
\hline Other & $1(0.5)$ & $1(0.5)$ & \\
\hline Marital status, n (\%) & & & 0.70 (NS) \\
\hline Single & $25(12.0)$ & $29(15.4)$ & \\
\hline Married & $146(69.9)$ & $133(70.7)$ & \\
\hline Divorced & $32(15.3)$ & $23(12.2)$ & \\
\hline Separated & $4(1.9)$ & $2(1.1)$ & \\
\hline Widowed & $2(1.0)$ & $1(0.5)$ & \\
\hline Education level, n (\%) & & & 0.65 (NS) \\
\hline$<$ High school & $21(10.0)$ & $20(10.6)$ & \\
\hline High school & $63(30.1)$ & $64(34.0)$ & \\
\hline$>$ High school & $125(59.8)$ & $104(55.3)$ & \\
\hline $\begin{array}{l}\text { Workers' compensa- } \\
\text { tion, } n(\%)\end{array}$ & $26(12.4)$ & $19(10.1)$ & 0.53 (NS) \\
\hline Alcohol used, n (\%) & $116(55.5)$ & $88(46.8)$ & 0.09 (NS) \\
\hline Preop work, n (\%) & $146(69.9)$ & $113(60.1)$ & 0.045 \\
\hline
\end{tabular}

NS $=$ not significant

for quantitative measurements (e.g., intervertebral angle, horizontal translation, FSU height). A third reviewer was used for adjudications.

\section{Statistical Methods}

The primary objective of the IDE clinical study was to demonstrate that the overall success rate in the Prestige LP ADR group was statistically noninferior to the overall success rate in the ACDF control group at 24 months after surgery, with a prespecified noninferiority margin of 0.10 . If noninferiority in overall success was established with respect to the control treatment, the investigational
TABLE 3. Preoperative presenting complaints for the Prestige LP ADR and ACDF groups

\begin{tabular}{lccc}
\hline \multicolumn{1}{c}{ Presenting Complaint } & $\begin{array}{c}\text { Prestige LP } \\
\text { ADR }(n=209)\end{array}$ & $\begin{array}{c}\text { ACDF } \\
(n=188)\end{array}$ & Significance \\
\hline Radiculopathy & $71.8 \%$ & $72.9 \%$ & NS \\
\hline Myelopathy & $2.4 \%$ & $3.2 \%$ & NS \\
\hline Radiculopathy \& myelopathy & $25.8 \%$ & $23.9 \%$ & NS \\
\hline
\end{tabular}

ADR treatment was considered to be safe and effective. For the purposes of this long-term follow-up, the primary end point, overall success, was evaluated at 36,60 , and 84 months. If noninferiority of the ADR treatment compared with the ACDF treatment in overall success was established, superiority in overall success at 36,60 , and 84 months was evaluated. Success rates for the individual effectiveness end points were also compared between the 2 treatment groups; when noninferiority of the investigational treatment was established, superiority was evaluated.

Bayesian statistical methods using noninformative priors in the Bayesian models were used for comparing differences in success rates between groups. When the posterior probability of noninferiority was at least $95 \%$, noninferiority of the Prestige LP ADR investigational device compared with the control was considered established. If noninferiority was found, superiority of the ADR group to the ACDF group was assessed in a similar fashion using the criterion of a posterior probability of superiority (PPS) of at least $95.0 \%$. Continuous measures, such as NDI score, SF-36 scores, and neck and arm pain scores, were also assessed using paired t-tests for improvement from pre- to postoperatively for each treatment group and were compared between the treatment groups using Bayesian methods. For all AEs and second surgical procedures, the $\log$ hazard ratio (LHR) of rates of occurrence between groups and the 95\% Bayesian credible interval (BCI) of highest posterior density were computed to determine whether the rates differed statistically between groups.

The outcomes of patients who underwent additional

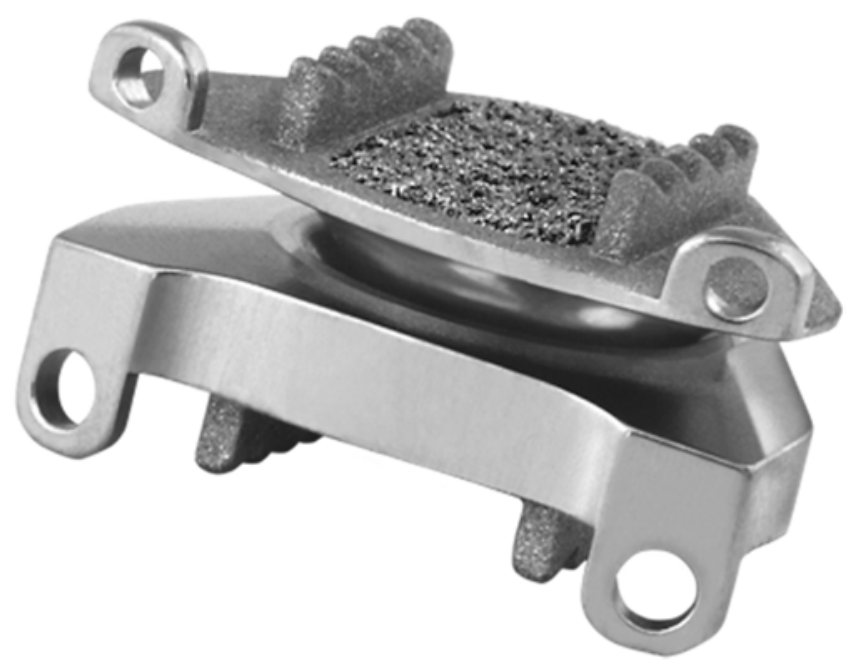

FIG. 2. The Prestige LP cervical disc. Courtesy of Medtronic. 
TABLE 4. Definitions of success

\begin{tabular}{|c|c|}
\hline Measure & Definition of Success \\
\hline NDI & Improvement of $\geq 15$ points \\
\hline Neck \& arm pain & Any improvement in score \\
\hline SF-36 PCS \& MCS & Any improvement in score \\
\hline Gait assessment (Nurick's classification) & Maintenance or improvement on preoperative score \\
\hline Radiographic measurements & $\begin{array}{l}\text { Maintenance of motion for the ADR group at both treated levels (angulation of target level }>4^{\circ} \text { but } \\
\leq 20^{\circ} \text { of angular motion, based on lateral flexion/extension radiographs \& no radiographic evidence } \\
\text { of bridging bone forming a continuous bony connection w/ the adjacent VBs) \& by evidence of } \\
\text { fusion for the ACDF group at both treated levels (angulation of target level } \leq 4^{\circ} \text { of angular motion, } \\
\text { based on lateral flexion/extension radiographs \& evidence of bridging bone, based on the evidence } \\
\text { of a continuous bony connection w/ VBs above \& below in at least } 1 \text { of the following areas: lateral, } \\
\text { anterior, posterior, \&/or through the allograft ring, \& no evidence of radiolucency covering }>50 \% \text { of } \\
\text { either the superior or inferior surface of the graft) }\end{array}$ \\
\hline Disc height (FSU) & $\begin{array}{l}\text { Postop follow-up FSU height minus } 6 \text {-wk postop FSU } \geq-2 \mathrm{~mm} \text { for both treated levels at either the } \\
\text { anterior or posterior measurement }\end{array}$ \\
\hline Patient satisfaction & Responses of "Definitely true" or "Mostly true" \\
\hline Patient global perceived effect & 1 of the 3 responses on the "Improved" end of the 7-point scale \\
\hline Foraminal compression test & Postop maintenance or improvement of preop status \\
\hline Physician's perception of results & An "excellent" or "good" response \\
\hline AEs & No Grade 3 or 4 implant/surgical procedure-associated $\mathrm{AE}$ \\
\hline $\begin{array}{l}\text { Neurological status for motor function, sensory } \\
\text { function, \& reflexes }\end{array}$ & Maintenance or improvement in all 3 functions \\
\hline 2nd surgery & None \\
\hline
\end{tabular}

surgical procedures/interventions were deemed failures for overall success, and since these additional surgical procedures/interventions had potential to alter the original study treatment's outcomes, for all neurological status and all individual effectiveness variables, the last observation obtained before the additional surgery occurred was carried forward for all subsequent observation periods. For comparison of preoperative measures, ANOVA was performed for continuous variables and Fisher's exact test for the categorical variables.

An independent statistical analysis using the same protocol approved by the FDA was performed for the 24-month and 60-month data by the Vanderbilt University Medical Center Biostatistics Collaboration Center. Results for both intervals were consistent with Medtronic's analyses and thus were not performed for other intervals.

\section{Results}

\section{Efficacy Success Rates}

Figure 3 shows the success rates and posterior probabilities of superiority for overall success, NDI, and neurological success over time. Superiority was established for ADR compared with ACDF for overall success rate and NDI at all postoperative intervals. The observed overall success rates for the ADR and ACDF groups were 81.6\% and $70.5 \%$ at 36 months postoperatively, respectively, $79.6 \%$ and $65.9 \%$ at 60 months, and $78.6 \%$ and $62.7 \%$ at 84 months. By 84 months, $87.0 \%$ of ADR patients met criteria for NDI success compared with $75.6 \%$ of the ACDF group. A similar difference was shown at 84 months for neurological success $(91.6 \%$ vs $82.1 \%, \mathrm{PPS}=99.0 \%)$.

\section{Individual Effectiveness Variables}

Observed mean scores over time for a number of the individual effectiveness variables, including NDI, neck pain, arm pain, and SF-36 PCS, are shown in Fig. 4. Both groups improved significantly over baseline on all of these measures (all $\mathrm{p}$ values $\leq 0.001$ ), with the ADR group showing superiority at all intervals for NDI score and neck pain score. SF-36 PCS showed superiority for the ADR group at long-term follow-up of 60 and 84 months, while arm pain score showed superiority for the ADR group at 24 and 60 months. Foraminal compression test results were negative in $98.0 \%$ and $94.2 \%$, of the ADR and ACDF groups, respectively.

\section{Bayesian Analyses}

Table 5 presents a summary of the Bayesian analysis to establish posterior probabilities of noninferiority and superiority and 95\% BCI of success for all of the effectiveness variables at 36,60 , and 84 months postoperatively. A probability of noninferiority of $\geq 95 \%$, allowing a claim of noninferiority of ADR compared with ACDF, was found for all efficacy variables at all test intervals. A posterior probability of at least $95.0 \%$, suggesting superiority of Prestige LP ADR, was found for overall success and NDI success at all time points, and for neurological success, neck pain success, and SF-36 PCS success at 1 or more intervals. Table 5 also shows the mean success probabilities for each efficacy variable based on the Bayesian analyses, as well as the lower and upper bounds of the $95 \%$ BCI and the difference in probabilities between the two groups. 


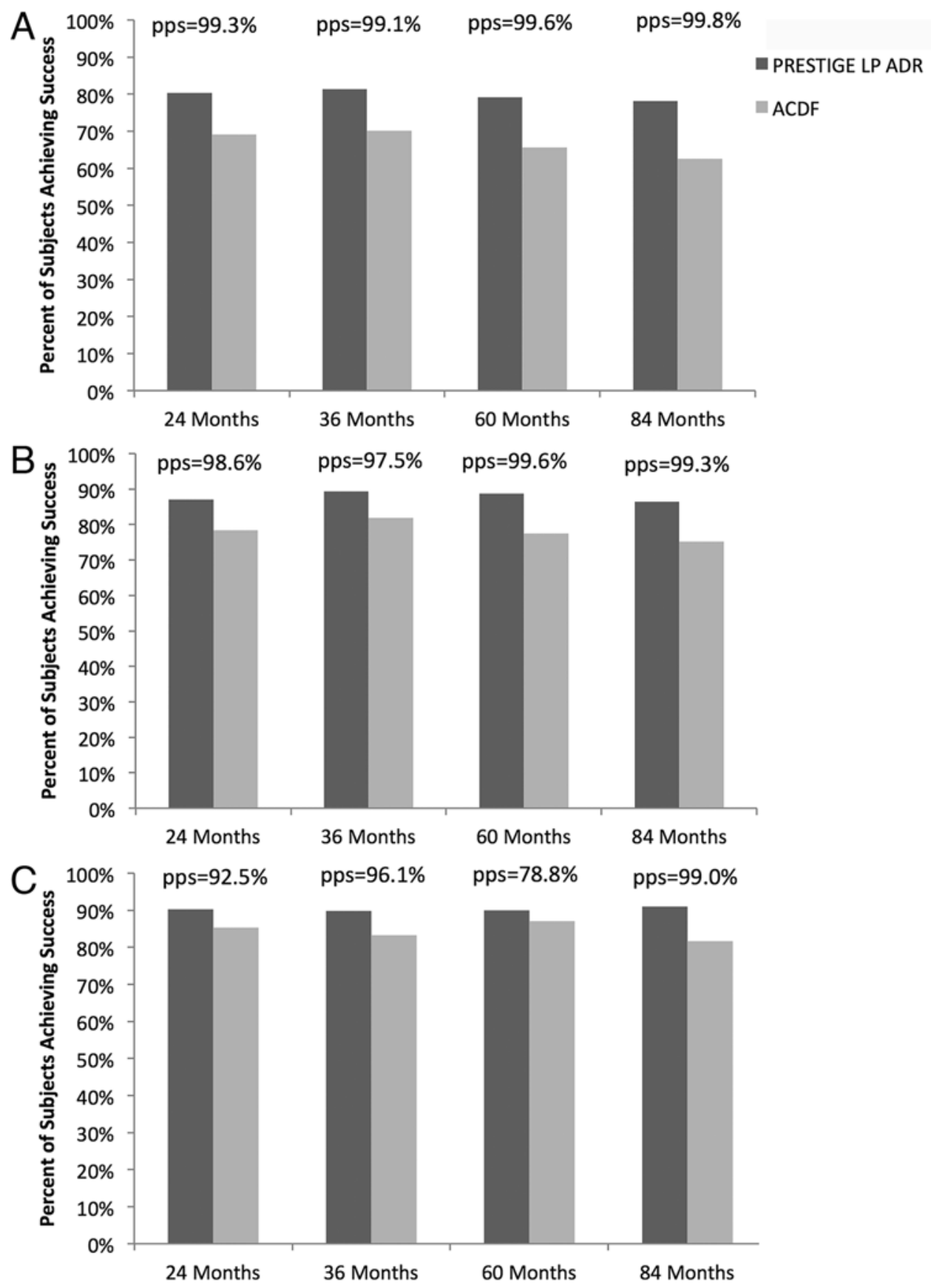

FIG. 3. Success rates over time for efficacy measures overall success $(\mathbf{A})$, NDI success $(\mathbf{B})$, and neurological success $(\mathbf{C})$. pps = posterior probability of superiority; pps $>95 \%$ considered as being statistically superior.

\section{Patient and Physician Perceptions}

At 84 months postoperatively, based on responses to the nonvalidated questionnaire, $94.8 \%$ of patients in the Prestige LP ADR group and $92.6 \%$ of the patients in the ACDF group reported that they were "definitely" or "mostly" satisfied, and $94.8 \%$ and $89.4 \%$, respectively, said they would undergo the surgery again for the same condition. The rates of physicians' perceptions of results as successful, also based on a nonvalidated questionnaire, were $95.4 \%$ and $78.9 \%$ for the 2 treatments, respectively. Preoperatively, $69.9 \%$ and $60.1 \%$ of the original study groups reported that they were employed, respectively. At 84 months, the percentages of patients working were $66.7 \%$ and $59.3 \%$, respectively.

\section{Radiographic Measurements}

FSU height was maintained in both groups, with overall success rates at 84 months of $90.6 \%$ and $92.7 \%$ for the 2 groups, respectively (Fig. 5). Angular range of motion (ROM) at superior and inferior target levels on average was maintained in the ADR group, with no statistically significant changes from preoperative to 84 months (Fig. 6). Fig- 


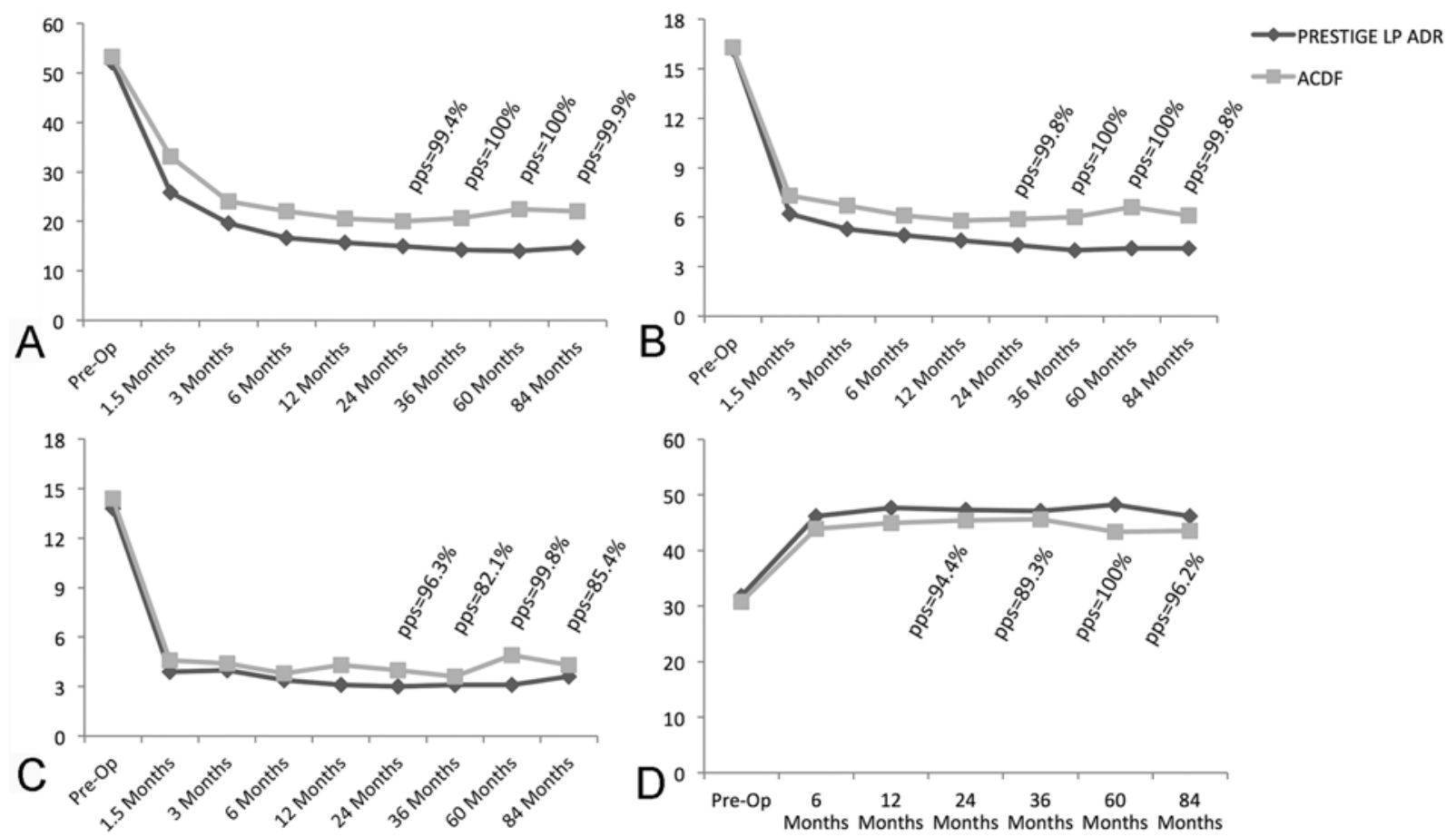

FIG. 4. Mean scores over time for efficacy measures NDI (A), neck (B) and arm (C) pain, and SF-36 PCS (D). For NDI, neck pain, and arm pain, a lower score indicates less disability or pain. For SF-36 PCS, a higher score means better functioning. pps = posterior probability of superiority; pps $>95 \%$ is considered as being statistically superior.

ure 7 is a radiograph showing a 2-level arthroplasty ROM at long-term follow-up (84 months). The fusion success rates for the ACDF group at 36 months, 60 months, and 84 months were $83.3 \%, 94.0 \%$, and $92.0 \%$, respectively. Some of the differences in fusion rates between intervals are likely due to the slightly different samples of patients over time because of death, withdrawal, being lost to follow-up (Fig. 1), and the independent radiological review, which was blinded to fusion status of each patient at previous intervals.

\section{Safety}

Table 6 summarizes the percentage of patients having any type of AE, cumulative through 84 months postoperatively. The ADR group had a statistically lower rate of any type of serious AEs and a lower rate of possibly device-related AEs. The rate of serious AEs (Grade 3 or 4) classified as implant or implant/surgical procedure associated was 3.2\% in the ADR group and 7.2\% in the ACDF group cumulatively through 84 months postoperatively (LHR -1.19 [95\% BCI -2.29 to -0.15$]$ ), and the prevalence of specific serious implant- or implant/surgical procedure-associated AEs is detailed in Table 7. All statistically significantly different comparison results favored the ADR group. Nearly all of the device- or procedure-related neurological AEs occurred within the first 6 months after

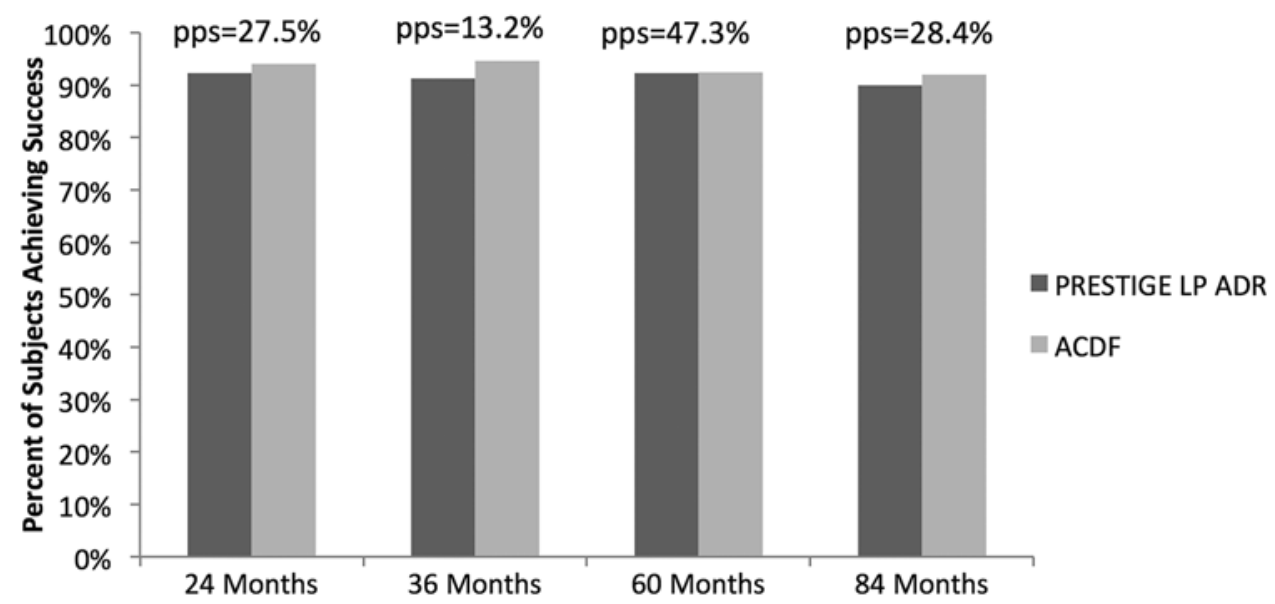

FIG. 5. FSU success rates for the Prestige LP ADR and ACDF groups over time. pps > 95\% considered as being statistically superior. 
TABLE 5. Summary of posterior probabilities of noninferiority and superiority and $95 \% \mathrm{BCl}$ of success for effectiveness variables at 36 , 60 , and 84 months postoperatively

\begin{tabular}{|c|c|c|c|c|c|c|c|c|c|c|c|}
\hline \multirow[b]{3}{*}{ Variable } & \multirow{3}{*}{$\begin{array}{c}\text { Probability of } \\
\text { Noninferiority } \\
(\text { delta }=0.10)(\%)\end{array}$} & \multirow{3}{*}{$\begin{array}{c}\text { Probability of } \\
\text { Superiority } \\
(\%)\end{array}$} & \multicolumn{9}{|c|}{ Posterior Mean \& 95\% BCl } \\
\hline & & & \multicolumn{3}{|c|}{ ACDF } & \multicolumn{3}{|c|}{ Prestige LP ADR } & \multicolumn{3}{|c|}{ ACDF - ADR* } \\
\hline & & & Mean & LB & UB & Mean & LB & UB & Mean & LB & UB \\
\hline \multicolumn{12}{|l|}{ Overall success } \\
\hline 36 mos & $\sim 100.0$ & 99.2 & 0.702 & 0.629 & 0.774 & 0.813 & 0.756 & 0.867 & -0.111 & -0.203 & -0.020 \\
\hline $60 \mathrm{mos}$ & $\sim 100.0$ & 99.6 & 0.657 & 0.578 & 0.734 & 0.793 & 0.731 & 0.853 & -0.136 & -0.234 & -0.036 \\
\hline 84 mos & 100.0 & 99.8 & 0.625 & 0.541 & 0.708 & 0.782 & 0.717 & 0.845 & -0.157 & -0.263 & -0.052 \\
\hline \multicolumn{12}{|l|}{ NDI success } \\
\hline 36 mos & $\sim 100.0$ & 97.5 & 0.819 & 0.757 & 0.879 & 0.893 & 0.848 & 0.935 & -0.074 & -0.151 & 0.001 \\
\hline $60 \mathrm{mos}$ & $\sim 100.0$ & 99.6 & 0.774 & 0.703 & 0.842 & 0.888 & 0.839 & 0.933 & -0.114 & -0.199 & -0.030 \\
\hline $84 \mathrm{mos}$ & 100.0 & 99.3 & 0.752 & 0.676 & 0.826 & 0.865 & 0.811 & 0.917 & -0.113 & -0.206 & -0.021 \\
\hline \multicolumn{12}{|c|}{ Neurological success } \\
\hline 36 mos & $\sim 100.0$ & 96.1 & 0.833 & 0.773 & 0.891 & 0.898 & 0.855 & 0.94 & -0.065 & -0.139 & 0.008 \\
\hline 60 mos & $\sim 100.0$ & 79.3 & 0.870 & 0.813 & 0.923 & 0.899 & 0.853 & 0.942 & -0.030 & -0.103 & 0.041 \\
\hline 84 mos & 100.0 & 99.0 & 0.816 & 0.748 & 0.882 & 0.91 & 0.865 & 0.953 & -0.094 & -0.176 & -0.014 \\
\hline \multicolumn{12}{|l|}{ FSU success } \\
\hline 36 mos & 98.7 & 13.2 & 0.946 & 0.906 & 0.981 & 0.913 & 0.869 & 0.954 & 0.033 & -0.026 & 0.091 \\
\hline 60 mos & 99.8 & 47.2 & 0.924 & 0.877 & 0.969 & 0.923 & 0.878 & 0.964 & 0.002 & -0.064 & 0.066 \\
\hline 84 mos & 98.4 & 28.4 & 0.92 & 0.869 & 0.966 & 0.899 & 0.847 & 0.948 & 0.02 & -0.053 & 0.092 \\
\hline \multicolumn{12}{|c|}{ Neck pain success } \\
\hline 36 mos & $\sim 100.0$ & 96.4 & 0.933 & 0.892 & 0.97 & 0.973 & 0.95 & 0.993 & -0.040 & -0.088 & 0.005 \\
\hline $60 \mathrm{mos}$ & $\sim 100.0$ & 97.4 & 0.912 & 0.865 & 0.957 & 0.964 & 0.936 & 0.989 & -0.052 & -0.108 & 0.001 \\
\hline 84 mos & 100.0 & 65.7 & 0.944 & 0.903 & 0.98 & 0.955 & 0.922 & 0.984 & -0.011 & -0.064 & 0.040 \\
\hline \multicolumn{12}{|c|}{ Arm pain success } \\
\hline 36 mos & 99.3 & 29.8 & 0.899 & 0.851 & 0.945 & 0.882 & 0.835 & 0.927 & 0.018 & -0.049 & 0.085 \\
\hline $60 \mathrm{mos}$ & 99.7 & 44.7 & 0.898 & 0.847 & 0.946 & 0.894 & 0.846 & 0.938 & 0.004 & -0.065 & 0.073 \\
\hline 84 mos & 96.1 & 18.1 & 0.904 & 0.852 & 0.953 & 0.87 & 0.817 & 0.921 & 0.034 & -0.04 & 0.108 \\
\hline \multicolumn{12}{|c|}{ SF-36 PCS success } \\
\hline 36 mos & 99.8 & 57.9 & 0.856 & 0.799 & 0.911 & 0.864 & 0.814 & 0.911 & -0.008 & -0.084 & 0.067 \\
\hline 60 mos & $\sim 100.0$ & 98.1 & 0.797 & 0.728 & 0.864 & 0.884 & 0.835 & 0.931 & -0.087 & -0.171 & -0.004 \\
\hline 84 mos & 100.0 & 93.2 & 0.795 & 0.723 & 0.865 & 0.863 & 0.808 & 0.915 & -0.068 & -0.158 & 0.021 \\
\hline \multicolumn{12}{|c|}{ SF-36 MCS success } \\
\hline 36 mos & 99.8 & 77.2 & 0.719 & 0.646 & 0.791 & 0.756 & 0.693 & 0.816 & -0.036 & -0.132 & 0.058 \\
\hline 60 mos & 99.4 & 70.8 & 0.722 & 0.645 & 0.796 & 0.750 & 0.683 & 0.814 & -0.028 & -0.129 & 0.072 \\
\hline 84 mos & 99.5 & 76.3 & 0.713 & 0.632 & 0.791 & 0.752 & 0.682 & 0.818 & -0.039 & -0.145 & 0.066 \\
\hline \multicolumn{12}{|l|}{ Gait success } \\
\hline 36 mos & $\sim 100.0$ & 93.5 & 0.967 & 0.938 & 0.992 & 0.989 & 0.975 & 1.000 & -0.023 & -0.057 & 0.008 \\
\hline $60 \mathrm{mos}$ & $\sim 100.0$ & 93.3 & 0.964 & 0.932 & 0.991 & 0.988 & 0.972 & 1.000 & -0.024 & -0.061 & 0.009 \\
\hline 84 mos & 100.0 & 60.4 & 0.976 & 0.949 & 0.997 & 0.981 & 0.959 & 0.998 & -0.005 & -0.041 & 0.029 \\
\hline
\end{tabular}

$\mathrm{LB}=$ lower bound; UB = upper bound.

* A negative mean difference indicates that the Prestige LP ADR treatment group had a higher success rate than the ACDF control treatment group.

the study surgery, and none of the neurological AEs in the ADR group were Grade 3 or 4 . The great majority of all other types of AEs occurred within the first 24 months postoperatively.

The presence of any Grade III or IV HO in the ADR group is summarized in Table 8, although no Grade III or IV HO AEs considered likely to be device related or clinically significant were reported (Table 7). Grade IV $\mathrm{HO}$ was observed on radiographs at either or both of the superior and inferior treatment levels in $11.5 \%$ and $11.9 \%$ of patients at 60 and 84 months, respectively.

The rates of a second surgery at the treated levels through 84 months were $4.2 \%$ and $14.7 \%$ for the ADR and ACDF groups, respectively, a statistically significant difference (LHR -1.29 [95\% BCI -2.12 to -0.46$]$ ) favoring the ADR group (Table 9). The ACDF group had statistically significant higher rates of elective removals and supplemental fixations. An elective removal in this trial was one in which the device was removed at the discretion of the investigator and/or the patient and was not the result of an AE. In the ACDF group, elective removals were typically performed at the discretion of the investigator during a surgical procedure on adjacent or other cervical levels requiring removal of the plate and placement of a new plate. In the ADR patients, one removal occurred at 40 days postoperatively because of radicular arm pain and a 


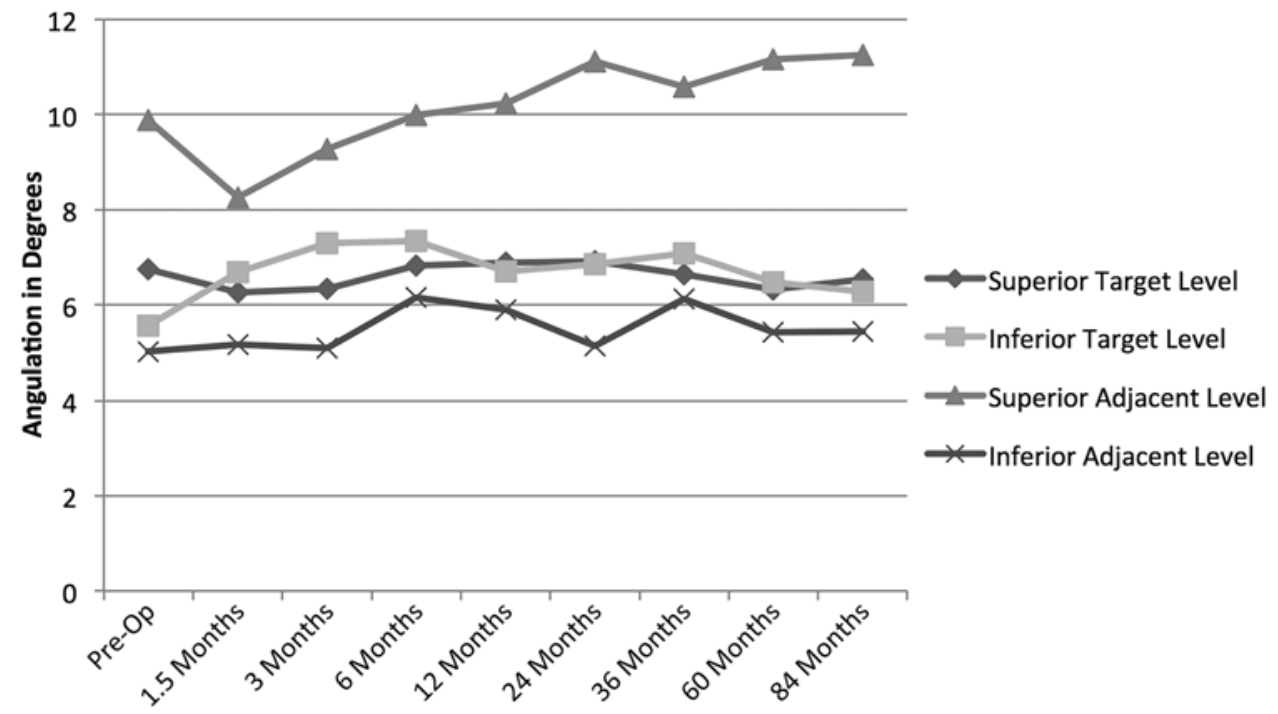

FIG. 6. Angular range of motion (ROM) for the Prestige LP ADR group over time at both the target and adjacent levels. Both superior and inferior levels are shown.

positive foraminal compression test, and another occurred at 1.3 years because of postsurgical cervical kyphosis and sagittal imbalance. The other removals occurred between 1.7 and 4.5 years postoperatively because of foraminal stenosis and other degenerative changes (2 cases), failed arthroplasty (1 case), and loosening of hardware with exacerbation of symptoms by a motor vehicle accident (1 case).

The cumulative rates of second surgeries that involved adjacent levels through 84 months after the clinical study treatment were $6.5 \%$ and $12.5 \%$ for the ADR and ACDF groups, respectively. Figure 8 demonstrates how the difference in rates of second surgeries between groups, although not significant, continued to increase over time, with a PPS at 84 months, falling just short of significance $(\mathrm{PPS}=94.2 \%)$.

\section{Discussion}

The primary objective for the original FDA-approved clinical study was to demonstrate noninferiority of investigational treatment (Prestige LP artificial cervical disc) over control treatment (ACDF) at 2 levels for symptomatic cervical DDD. At 60 months and 84 months postop-
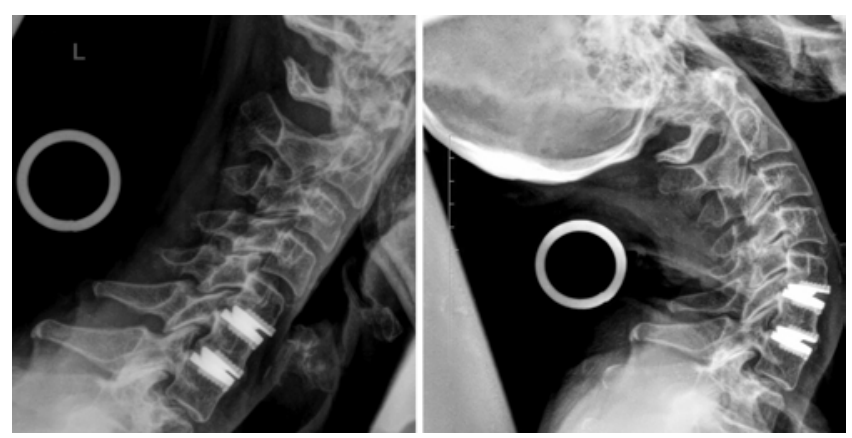

FIG. 7. Flexion (left) and extension (right) radiographs obtained in a patient in whom a Prestige LP ADR was placed, showing ROM at 84 months postoperatively. eratively, the Prestige LP ADR group had superior results compared with the ACDF group in terms of overall success and NDI success and was noninferior on all of the effectiveness outcome measures. At 60 months, the Prestige LP group also showed superiority in SF-36 PCS success, while at 84 months it did so for neurological success. By 84 months, the vast majority of patients in both groups reported satisfaction with their surgery ( $>92 \%$ in both groups). FSU height was maintained in both groups. The device served in the ADR group to maintain distraction of the disc space. Clinically significant AEs (Grade 3 or 4) that were considered to possibly be associated with the implant or implant/surgical procedure occurred significantly less frequently in the ADR group (3.2\% vs $7.2 \%$ ), as was the rate of second surgeries (4.2\% vs $14.7 \%)$. Finally, the rates of adjacent-level surgery up to 84 months after the clinical study treatment were higher in the ACDF group. Although this difference did not achieve statistical significance (PPS $=94.2 \%$ ), the trend appears clear, and the rates continue to diverge over time (Fig. 8).

A recent meta-analysis reviewing 19 randomized controlled trials involving 4516 cases demonstrated better outcomes for TDR compared with ACDF on a wide variety of measures. ${ }^{24}$ The potential benefits of 2-level TDR for intractable radiculopathy or myelopathy of the cervical spine are similar to those of single-level TDR: motion preservation and diminished stress on adjacent levels. Maintaining mobility at the 2 surgically treated segments better preserves the normal cervical spine biomechanics, protecting the integrity of adjacent segments, and possibly resulting in better patient outcomes for TDR than ACDF patients at 2 levels. One meta-analysis has suggested that outcomes for patients undergoing single-level or multilevel TDR were equally favorable, ${ }^{25}$ as did a recent individual study. ${ }^{1}$ And, as in the current study, others have found that outcomes after 2-level TDR were superior to outcomes after 2-level ACDF.? However, we believe that this is the first study to report results through 84 months postoperatively 
TABLE 6. Percentage of patients who reported AEs cumulative through 84 months postoperatively

\begin{tabular}{lccc}
\hline \multicolumn{1}{c}{ Variable } & Prestige LP ADR $(\mathrm{n}=209)$ & ACDF $(\mathrm{n}=188)$ & Log Hazard Ratio $(95 \% \mathrm{BCI})$ \\
\hline$\geq 1$ of any AEs & 99.1 & 98.2 & $0.019(-0.18$ to 0.21$), \mathrm{NS}$ \\
\hline Any serious AEs & 56.7 & 68.2 & $-0.38(-0.65$ to -0.11$)$ \\
\hline Possibly device-related AEst & 26.6 & 27.7 & $-0.13(-0.55$ to 0.26$), \mathrm{NS}$ \\
\hline Serious, possibly device-related AEs & 3.2 & 7.2 & $-1.19(-2.29$ to -0.15$)$ \\
\hline
\end{tabular}

* WHO Grade 3 or 4 adverse events are considered as serious.

$\dagger$ Those deemed to be associated with device or device/surgical procedure.

for an ADR device used at 2 levels, showing the long-term maintenance of results with the Prestige LP and its continued superiority over time to ACDF.

A possible source of bias in this study that might favor an investigational device is the lack of blinding, which is just not possible in this type of study. However, a number of measures were taken to preclude bias: radiological assessments were made by independent reviewers, AEs were evaluated by an independent committee, and statistical analyses were confirmed by statisticians independent of the study sponsor for the 24-month and 60-month data. Patient bias in reporting satisfaction, pain, and so on, could occur, but it seems unlikely that any such bias would sustain itself over long-term follow-up-in this study, 84 months. Not unexpectedly, we were unable to obtain follow-up on all patients through 84 months (7 years). However, the loss to follow-up rates were similar between the groups and results were consistent with those found for earlier intervals so this likely did not produce selection bias that would affect the comparison between groups.

\section{Conclusions}

The low-profile artificial cervical disc in this study,

TABLE 7. Percentage of patients with Grade 3 or 4 implant or implant/surgical procedure-associated AE cumulative through 84 months

\begin{tabular}{|c|c|c|c|}
\hline$A E$ & $\begin{array}{l}\text { Prestige } \\
\text { LP ADR }\end{array}$ & ACDF & $\operatorname{LHR}(95 \% \mathrm{BCl})$ \\
\hline Grade 3 or 4 AEs & $3.2 \%$ & $7.2 \%$ & $-1.19(-2.29$ to -0.15$)$ \\
\hline $\begin{array}{l}\text { Dysphagia/dys- } \\
\text { phonia }\end{array}$ & $1.3 \%$ & $0.0 \%$ & $796.21(-2.32$ to 1961.21$), \mathrm{NS}$ \\
\hline $\mathrm{HO}$ & $0.0 \%$ & $1.6 \%$ & $-798.33(-1957.40$ to -0.77$)$ \\
\hline Implant events & $1.0 \%$ & $1.6 \%$ & $-0.6601(-2.68$ to 1.36$), \mathrm{NS}$ \\
\hline $\begin{array}{l}\text { Neck \&/or arm } \\
\text { pain }\end{array}$ & $0.5 \%$ & $3.1 \%$ & $-2.24(-4.94$ to 0.15$), \mathrm{NS}$ \\
\hline Neurological & $0.0 \%$ & $1.9 \%$ & $-796.16(-1955.69$ to -0.49$)$ \\
\hline Nonunion & $0.0 \%$ & $5.6 \%$ & $-802.05(-1969.11$ to -1.43$)$ \\
\hline Other & $0.5 \%$ & $0.6 \%$ & $-0.17(-3.77$ to 3.44$), N S$ \\
\hline Spinal event & $1.5 \%$ & $3.3 \%$ & $-0.94(-2.46$ to 0.52$), \mathrm{NS}$ \\
\hline Trauma & $0.0 \%$ & $0.6 \%$ & $-797.62(-1958.28$ to 1.34$), \mathrm{NS}$ \\
\hline Vascular & $0.5 \%$ & $0.0 \%$ & $795.87(-1.45$ to 1953.08$), \mathrm{NS}$ \\
\hline $\begin{array}{l}\text { Wound (noninfec- } \\
\text { tious) }\end{array}$ & $0.0 \%$ & $0.5 \%$ & $-795.68(-1959.00$ to 1.30$), \mathrm{NS}$ \\
\hline
\end{tabular}

Prestige LP, implanted at 2 adjacent levels, maintains improved clinical outcomes and segmental motion 84 months after surgery. It was statistically noninferior to ACDF in every outcome measure and was statistically superior in overall success rate as well as other measures at 60 months and 84 months after surgery, while having a significantly lower rate of serious adverse effects possibly related to the procedure or device and a lower rate of second surgeries. This makes the Prestige LP artificial cervical disc an effective alternative to standard fusion treatment in patients with DDD associated with intractable radiculopathy or myelopathy at 2 adjacent levels of the cervical spine.

\section{Appendix}

The following is a list of other principal investigators who participated in the clinical trial: Mark Adams, MD, Adams Neurosurgery, Saginaw, MI; Carter Beck, MD, Montana Neuroscience Institute, Missoula, MT; Gary Bloomgarden, MD, Orchard Medical Center, New Haven, CT; Isa Canavati, MD, NeuroSpine \& Pain Center, Fort Wayne, IN; James Chadduck, MD, Virginia Brain and Spine, Winchester, VA; Wayne Cheng, MD, LLU Orthopedic Group, Loma Linda, CA; Frank J. Coufal, MD, La Jolla Neurosurgical Associates, La Jolla, CA; Doug Ehrler, MD, Crystal Clinic, Inc., Akron, OH; Sanford Emery, MD, MBA, West Virginia University Department of Orthopaedics, Morgantown, WV; Mokbel Chedid, MD, Henry Ford Health System, West Bloomfield, MI; Kevin Gibbons, MD, University at Buffalo Neurosurgery and Kaleida Health-Buffalo General Medical Center/Global Vascu-

TABLE 8. Percentage of patients with Grade III and IV HO for superior and inferior levels over time for the Prestige LP ADR group

\begin{tabular}{crrc}
\hline $\begin{array}{c}\text { Follow-Up Period } \\
\& \text { HO Grade }\end{array}$ & $\begin{array}{c}\text { Superior } \\
\text { Level }\end{array}$ & $\begin{array}{c}\text { Inferior } \\
\text { Level }\end{array}$ & $\begin{array}{c}\text { Either or } \\
\text { Both Levels }\end{array}$ \\
\hline 36 mos $(\mathrm{n}=184)$ & & & \\
\hline III & $14.1 \%$ & $21.2 \%$ & \\
\hline IV & $4.9 \%$ & $4.9 \%$ & $7.6 \%$ \\
\hline III or IV & $19.0 \%$ & $26.1 \%$ & $32.1 \%$ \\
\hline 60 mos $(\mathrm{n}=165)$ & & & \\
\hline III & $19.4 \%$ & $20.0 \%$ & \\
\hline IV & $8.5 \%$ & $8.5 \%$ & $11.5 \%$ \\
\hline III or IV & $27.9 \%$ & $28.5 \%$ & $38.8 \%$ \\
\hline 84 mos $(n=151)$ & & & \\
\hline III & $25.8 \%$ & $25.2 \%$ & \\
\hline IV & $8.6 \%$ & $7.3 \%$ & $11.9 \%$ \\
\hline III or IV & $34.4 \%$ & $32.5 \%$ & $42.4 \%$ \\
\hline
\end{tabular}


TABLE 9. Second surgeries, including number of events and number and percentage of patients cumulative through 84 months postoperatively, based on the life-table method

\begin{tabular}{|c|c|c|c|c|c|}
\hline \multirow[b]{2}{*}{ Variable } & \multicolumn{2}{|c|}{ Prestige LP ADR } & \multicolumn{2}{|c|}{ ACDF } & \multirow[b]{2}{*}{$\operatorname{LHR}(95 \% \mathrm{BCl})$} \\
\hline & Events & Patients & Events & Patients & \\
\hline 2nd op at index level ${ }^{*}$ & 10 & $8(4.2 \%)$ & 27 & $22(14.7 \%)$ & $-1.29(-2.12$ to -0.46$)$ \\
\hline Revision & 0 & $0(0.0 \%)$ & 1 & $1(0.5 \%)$ & $-795.68(-1958.99$ to 1.29$), \mathrm{NS}$ \\
\hline Removal & 6 & $6(3.2 \%)$ & 6 & $6(3.4 \%)$ & $-0.18(-1.36$ to 1.01$), N S$ \\
\hline Elective & 0 & $0(0.0 \%)$ & 6 & $6(4.3 \%)$ & $-798.67(-1963.72$ to -1.32$)$ \\
\hline Supplemental fixation & 1 & $1(0.5 \%)$ & 7 & $7(5.5 \%)$ & $-2.64(-5.34$ to -0.36$)$ \\
\hline Reop & 3 & $3(1.6 \%)$ & 7 & $5(3.1 \%)$ & -0.7861 ( -2.36 to 0.71$), \mathrm{NS}$ \\
\hline Supplemental fixation BGS† & 0 & $0(0.0 \%)$ & 5 & $5(2.8 \%)$ & $-799.25(-1962.07$ to -1.76$)$ \\
\hline 2nd op at adjacent level & 12 & $12(6.5 \%)$ & 22 & $17(12.5 \%)$ & -0.5937 ( -1.35 to 0.156$), \mathrm{NS}$ \\
\hline
\end{tabular}

BGS = external bone growth stimulator.

* Some patients had more than 1 second surgery.

$\dagger$ Not included in the total number of second surgeries at the treated level.

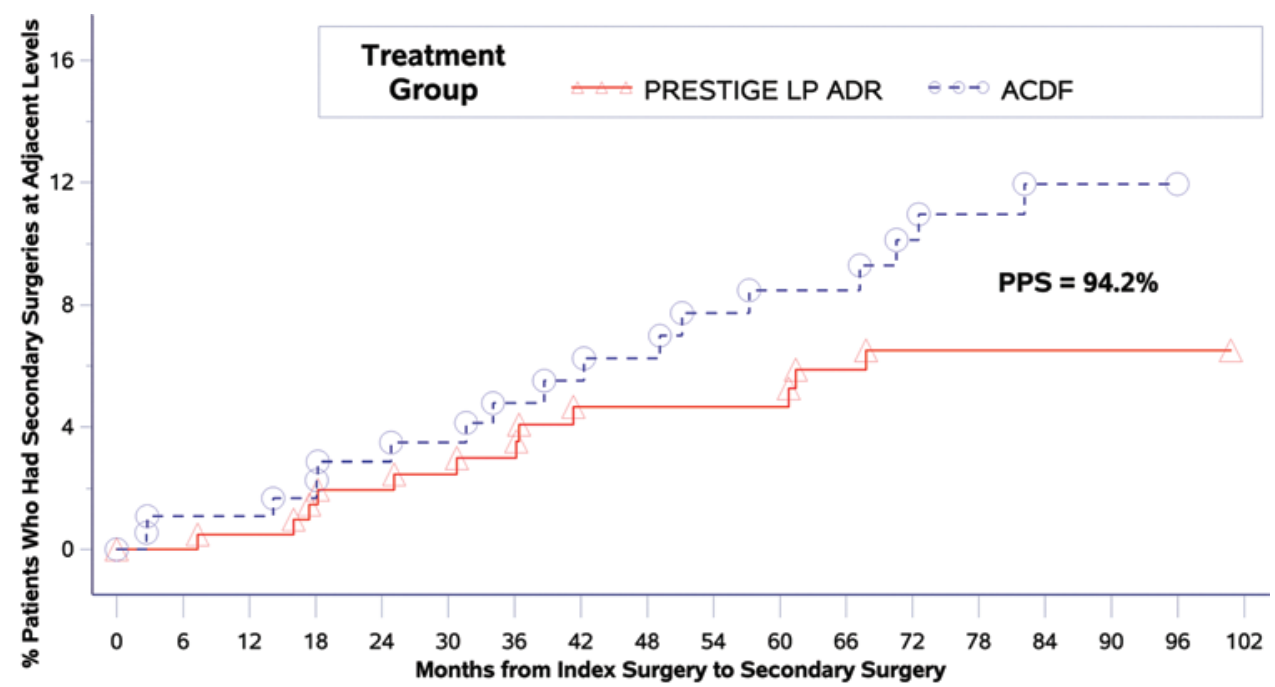

FIG. 8. Rates of second surgeries at an adjacent level over time for the Prestige LP ADR and ACDF groups. pps > 95\% is considered as being statistically superior.

lar Institute, Department of Neurosurgery, Buffalo, NY; Jeremy Greenlee, MD, University of Iowa Hospitals \& Clinics, Iowa City, IA; Brett Gunter, MD, Columbia Neurosurgical Associates, West Columbia, SC; Kenneth Hsu, MD, St. Mary's Hospital and Medical Center Spine Center, San Francisco, CA; John F. Keller, MD, Great Lakes Neurosurgical, Grand Rapids, MI; Yakov Koyfman, MD, Delaware Neurosurgical Group, Newark, DE; P. Jeffrey Lewis, MD, Buffalo Neurosurgery Group, West Seneca, NY; Christopher Lycette, MD, Neurosurgical Associates of LVPG, Bethlehem, PA; Bradford Mullin, MD, Central Ohio Neurological Surgeons, Inc., Westerville, OH; Larry Parker, MD, The Orthopedic Center, Huntsville, AL; Michael W. Reed, MD, Spinal Associates, Panama City, FL; Raymond Tien, MD, PhD, The Center Orthopedic \& Neurological Care \& Research, Bend, OR; Christopher Tomaras, MD, Peachtree Neurosurgery, Atlanta, GA; Donald M. Whiting, MD, Alleghany General Hospital, Department of Neurosurgery/Clinical Research, Pittsburgh, PA; and David A. Wiles, MD, East Tennessee Brain \& Spine Center, Johnson City, TN.

\section{Acknowledgments}

We would like to thank Karen I. Berliner, $\mathrm{PhD}$, who provided significant help with manuscript preparation and editing, and
Emily Funsten, who also helped in manuscript preparation. We would also like to acknowledge biostatisticians Feng Tang, PhD, Jay Dong, $\mathrm{PhD}$, and $\mathrm{Li} \mathrm{Ni}, \mathrm{PhD}$, of Medtronic for their contributions.

\section{References}

1. Bae HW, Kim KD, Nunley PD, Jackson RJ, Hisey MS, Davis RJ, et al: Comparison of clinical outcomes of 1- and 2-level total disc replacement: Four-year results from a prospective, randomized, controlled, multicenter IDE clinical trial. Spine (Phila Pa 1976) 40:759-766, 2015

2. Burkus JK, Haid RW, Traynelis VC, Mummaneni PV: Longterm clinical and radiographic outcomes of cervical disc replacement with the Prestige disc: results from a prospective randomized controlled clinical trial. J Neurosurg Spine 13:308-318, 2010

3. Burkus JK, Traynelis VC, Haid RW Jr, Mummaneni PV: Clinical and radiographic analysis of an artificial cervical disc: 7-year follow-up from the Prestige prospective randomized controlled clinical trial: Clinical article. J Neurosurg Spine 21:516-528, 2014

4. Cappelletto B, Giorgiutti F, Veltri C, Trevigne MA, Facchin 
P, Del Fabro P: Disc prosthesis replacement and interbody fusion in the treatment of degenerative cervical disc disease: comparative analysis of 176 consecutive cases. Eur Spine J 22 (6 Suppl 6):S894-S899, 2013

5. Chang UK, Kim DH, Lee MC, Willenberg R, Kim SH, Lim $\mathrm{J}$ : Changes in adjacent-level disc pressure and facet joint force after cervical arthroplasty compared with cervical discectomy and fusion. J Neurosurg Spine 7:33-39, 2007

6. Coric D, Nunley PD, Guyer RD, Musante D, Carmody CN, Gordon CR, et al: Prospective, randomized, multicenter study of cervical arthroplasty: 269 patients from the KineflexlC artificial disc investigational device exemption study with a minimum 2-year follow-up: clinical article. J Neurosurg Spine 15:348-358, 2011

7. Davis RJ, Kim KD, Hisey MS, Hoffman GA, Bae HW, Gaede SE, et al: Cervical total disc replacement with the Mobi-C cervical artificial disc compared with anterior discectomy and fusion for treatment of 2-level symptomatic degenerative disc disease: a prospective, randomized, controlled multicenter clinical trial: clinical article. J Neurosurg Spine 19:532-545, 2013

8. Dmitriev AE, Cunningham BW, Hu N, Sell G, Vigna F, McAfee PC: Adjacent level intradiscal pressure and segmental kinematics following a cervical total disc arthroplasty: an in vitro human cadaveric model. Spine (Phila Pa 1976) 30:1165-1172, 2005

9. Gornet MF, Burkus JK, Shaffrey ME, Argires PJ, Nian H, Harrell FE Jr: Cervical disc arthroplasty with PRESTIGE LP disc versus anterior cervical discectomy and fusion: a prospective, multicenter investigational device exemption study. J Neurosurg Spine 23:558-573, 2015

10. Gornet MF, Lanman TH, Burkus JK, Hodges SD, McConnell JR, Dryer RF, et al: Cervical disc arthroplasty with the Prestige LP disc versus anterior cervical discectomy and fusion, at 2 levels: results of a prospective, multicenter randomized controlled clinical trial at 24 months. J Neurosurg Spine [epub ahead of print March 17, 2017. DOI: 10.3171/2016.10. SPINE16264]

11. Heller JG, Sasso RC, Papadopoulos SM, Anderson PA, Fessler RG, Hacker RJ, et al: Comparison of BRYAN cervical disc arthroplasty with anterior cervical decompression and fusion: clinical and radiographic results of a randomized, controlled, clinical trial. Spine (Phila Pa 1976) 34:101-107, 2009

12. Lopez-Espina CG, Amirouche F, Havalad V: Multilevel cervical fusion and its effect on disc degeneration and osteophyte formation. Spine (Phila Pa 1976) 31:972-978, 2006

13. McDowell I: Measuring Health, A Guide to Rating Scales and Questionnaires. New York: Oxford University Press, 1996

14. Mummaneni PV, Burkus JK, Haid RW, Traynelis VC, Zdeblick TA: Clinical and radiographic analysis of cervical disc arthroplasty compared with allograft fusion: a randomized controlled clinical trial. J Neurosurg Spine 6:198-209, 2007

15. Murrey D, Janssen M, Delamarter R, Goldstein J, Zigler J, Tay B, et al: Results of the prospective, randomized, controlled multicenter Food and Drug Administration investigational device exemption study of the ProDisc-C total disc replacement versus anterior discectomy and fusion for the treatment of 1-level symptomatic cervical disc disease. Spine J 9:275-286, 2009

16. Nurick S: The pathogenesis of the spinal cord disorder associated with cervical spondylosis. Brain 95:87-100, 1972

17. Robertson JT, Papadopoulos SM, Traynelis VC: Assessment of adjacent-segment disease in patients treated with cervical fusion or arthroplasty: a prospective 2-year study. J Neurosurg Spine 3:417-423, 2005

18. Shi R, Li J, Liu H, Ding C, Hu T, Li T, et al: Clinical comparison of 2 implantation systems for single-level cervical disk replacement. Orthopedics 37:e161-e168, 2014

19. Swank ML, Lowery GL, Bhat AL, McDonough RF: Anterior cervical allograft arthrodesis and instrumentation: multilevel interbody grafting or strut graft reconstruction. Eur Spine J 6:138-143, 1997

20. Veeravagu A, Cole T, Jiang B, Ratliff JK: Revision rates and complication incidence in single- and multilevel anterior cervical discectomy and fusion procedures: an administrative database study. Spine J 14:1125-1131, 2014

21. Vernon H, Mior S: The Neck Disability Index: a study of reliability and validity. J Manipulative Physiol Ther 14:409415, 1991

22. Wang CS, Chang JH, Chang TS, Chen HY, Cheng CW: Loading effects of anterior cervical spine fusion on adjacent segments. Kaohsiung J Med Sci 28:586-594, 2012

23. Ware JE, Kosinski M, Keller SK: SF-36 Physical and Mental Health Summary Scales: A User's Manual. Boston: The Health Institute, 1994

24. Zhang Y, Liang C, Tao Y, Zhou X, Li H, Li F, et al: Cervical total disc replacement is superior to anterior cervical decompression and fusion: a meta-analysis of prospective randomized controlled trials. PLoS One 10:e0117826, 2015

25. Zhao H, Cheng L, Hou Y, Liu Y, Liu B, Mundra JJ, et al: Multi-level cervical disc arthroplasty (CDA) versus singlelevel CDA for the treatment of cervical disc diseases: a metaanalysis. Eur Spine J 24:101-112, 2015

\section{Disclosures}

All authors participated in the clinical trial of the Prestige LP, which was sponsored by Medtronic, Inc. The sponsor reviewed the manuscript for technical accuracy and also provided the statistical analysis. The sponsor provided access to the data and statistical analyses. The authors disclose the following. Dr. Lanman: consultant for and patent holder with Medtronic. Dr. Burkus: consultant for Medtronic, and received clinical/research support for this study and statistical analysis for study/writing or editorial assistance from Medtronic. Dr. Gornet: direct stock ownership in Bonovo, International Spine \& Orthopedic Institute, LLC, Nocimed, OuroBoros, and Viscogliosi Bros Venture Partners, LLC; and consultant for K2M, and Medtronic. Dr. McConnell: Consultant for Globus Medical Inc., Medtronic, and DePuy/Synthes, and direct stock ownership in Globus Medical Inc.

\section{Author Contributions}

Conception and design: Lanman, Gornet. Acquisition of data: Lanman, Burkus, McConnell, Hodges. Analysis and interpretation of data: Lanman, Burkus, Dryer, Gornet. Drafting the article: Lanman, Gornet. Critically revising the article: all authors. Reviewed submitted version of manuscript: Lanman, Burkus, Dryer, McConnell, Hodges. Approved the final version of the manuscript on behalf of all authors: Lanman. Study supervision: Lanman, Gornet.

\section{Correspondence}

Todd H. Lanman, Institute for Spinal Disorders, $450 \mathrm{~N}$ Roxbury Dr., 3rd Fl., Beverly Hills, CA 90210. email: lanman3@gmail.com. 